\title{
The modulatory effect of green tea catechin on drug resistance in human ovarian cancer cells
}

\author{
Dawid Przystupski $^{1}$ - Olga Michel ${ }^{2} \cdot$ Joanna Rossowska $^{3}$ - Stanisław Kwiatkowski ${ }^{1}$ - Jolanta Saczko ${ }^{4}$. \\ Julita Kulbacka $\mathbb{1}^{4}$
}

Received: 11 October 2018 / Accepted: 1 March 2019 / Published online: 16 March 2019

(c) The Author(s) 2019

\begin{abstract}
Numerous in vitro and in vivo studies have demonstrated the antiproliferative effect of green tea. It has been speculated that one of its compounds - catechin, may affect multidrug resistance (MDR) phenomena. We examined the effect of catechin and cisplatin on human ovarian cancer cells' SKOV-3 viability. It was also studied whether preincubation with catechin modulates drug resistance revealed by SKOV-3 cells. Catechin at concentrations up to $200 \mu \mathrm{M}$ has been shown to be slightly toxic to the tested cells. Analysis of cells after preincubation with catechin revealed increased cytotoxicity of cisplatin compared to the cells treated only with cytostatic and changed expression of MDR-related proteins. Pre-treatment with catechin enhanced cisplatin cytotoxicity by promoting apoptosis and changing activity of membrane proteins involved in drug metabolism, uptake and efflux, especially P-glycoprotein, GST, LRP and BCRP. The obtained results and available reports prove that catechin and its derivatives can potentially be used in chemotherapy as a modulator of MDR phenomena.
\end{abstract}

\section{Graphical Abstract}

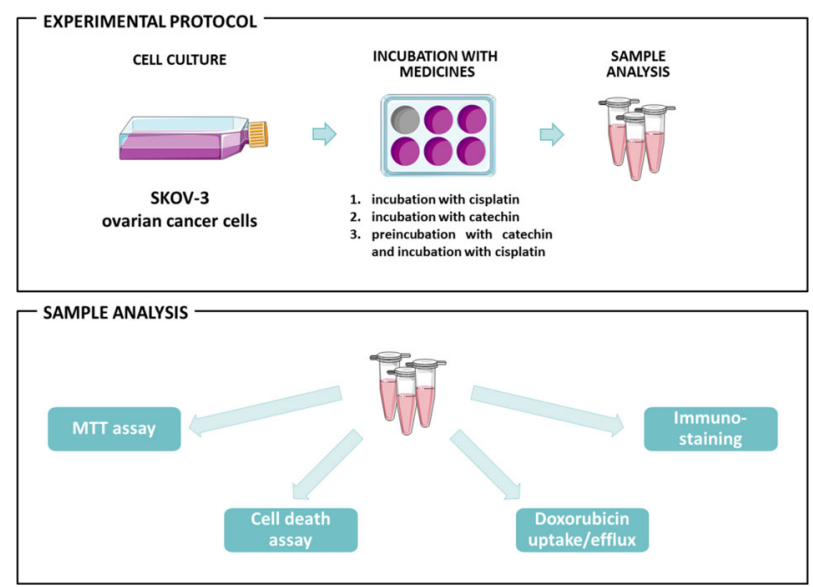

Supplementary information The online version of this article (https:// doi.org/10.1007/s00044-019-02324-6) contains supplementary material, which is available to authorised users.

Dawid Przystupski

dawid.przystupski@gmail.com

$\triangle$ Julita Kulbacka

julita.kulbacka@umed.wroc.pl

1 Faculty of Medicine, Wroclaw Medical University, J. MikuliczaRadeckiego 5, 50-345 Wroclaw, Poland
2 Department of Medical Biochemistry, Wroclaw Medical University, Chalubinskiego 10, 50-368 Wroclaw, Poland

3 Institute of Immunology and Experimental Therapy Polish Academy of Sciences, Rudolfa Weigla 12, 53-114 Wroclaw, Poland

4 Department of Molecular and Cellular Biology, Wroclaw Medical University, Borowska 211 A, 50-556 Wroclaw, Poland 
Keywords Catechin $\cdot$ Green Tea $\cdot$ Ovarian cancer $\cdot$ Multidrug resistance

\section{Introduction}

\section{Epithelial ovarian cancer}

Epithelial ovarian cancer is one of the most mortal forms of gynaecological malignancies, affecting over two hundred thousand women around the world each year (Helm and States 2009). High mortality is associated with poor prognosis, early asymptomatic character and heterogeneous nature of the tumour (Zhang et al. 2009). Most often, ovarian cancer is diagnosed at an advanced stage in which tumours are spread outside the ovaries in about two thirds of patients (Schuijer and Berns 2003). The basis for the firstline treatment is combined management, which includes surgery and chemotherapy with cisplatin (Kornafel and Mądry 2013). Severe complications occurring after the standard chemotherapeutic protocols (nausea, blood disorders, nerve damage etc.) implicate necessity of the search for more effective and less-radical therapies where substances of natural origin, including polyphenols presented in green tea, can be used. Previous clinical analyses confirmed the anti-cancer effect of catechins. Zhang et al. (2015a, $2015 b)$ observed the effects of the green tea consumption for a minimum of 3 years in 244 women diagnosed with ovarian cancer. A group of women who drank green tea had a lower risk of dying of ovarian cancer (hazard ratio $(\mathrm{HR})=0.55$; confidence interval $(\mathrm{CI}) 95 \%: 0.34-0.90$ ) The mean survival time for people drinking green tea was 5.39 (95\% CI: 4.94, 5.85) and 4.19 (95\% CI: 3.66, 4.72) among non-drinkers. When women started taking green tea only after the diagnosis, the average survival time among patients drinking green tea was almost two years longer compared to women who did not consume it (Zhang et al. 2015a).

\section{Green tea catechins}

Numerous in vitro and in vivo studies have demonstrated the antiproliferative effect of green tea extracts (Schuijer and Berns 2003; Zhang et al. 2009), which has been attributed to the biological properties of polyphenolic compounds (Asano et al. 1997; Hussain et al. 2005). In vitro studies have revealed that polyphenols can inhibit the growth of human breast, lung, colorectal and prostate cancer cells, lymphoma cells and leukaemic cells (Paschka and Butler 1998; Yang et al. 2009). The most abundant polyphenol of green tea is epigallocatechin gallate (EGCG). In addition to EGCG, green tea contains other polyphenols, such as epicatechin gallate, epigallocatechin, epicatechin and catechin, which show antiviral properties. Catechins are one of the strongest antioxidants and the long-term consumption of green tea extracts increases the activity of glutathione S-transferase (GST), an enzyme involved in detoxification (Song et al. 2014). It also limits the formation of new capillaries, which enable glucose and oxygen to penetrate the cancer, thereby reducing the risk of tumour metastasis. Epicatechin increases the expression of oxidative stress enzymes, (e.g. superoxide dismutase) and inhibits the expression of lipo- and cyclooxygenase, xanthine oxidase, activator protein 1 and NF- $\mathrm{KB}$ transcription factors (Hosseinimehr et al. 2013). According to the recent studies, catechins contained in green tea may alter drug resistance by affecting or modulating membrane proteins from the ABC family (Amin 2013; Song et al. 2014). Furthermore, catechins may also affect the expression of other proteins related to the multidrug resistance, such as breast cancer resistance protein (BCRP) (Tang et al. 2008; Sugihara et al. 2017). Due to the serious clinical implications resulting from the MDR occurrence, many studies have focused on the search for medicines reversing the multidrug resistance phenomenon. Accordingly, we hypothesized that catechin may enhance the efficacy of cytostatic compounds used in oncology, including cisplatin.

\section{Material and methods}

\section{Cell culture}

The research was carried out on human ovarian cancer cells SKOV-3 resistant to tumor necrosis factor and to several cytotoxic drugs including diphtheria toxin, cisplatin and Adriamycin (ATCC, Manassas, VA, USA). The cells were grown in monolayer on polystyrene bottles with a cell culture area of $75 \mathrm{~cm}^{2}$ (Falcon, Becton, Dickinson and Co., Franklin Lakes, NJ) in Dulbecco's modified Eagle's Medium (DMEM, Sigma-Aldrich, St. Louis, MO) containing $2 \mathrm{mM}$ L-glutamine, $10 \%$ fetal bovine serum (FBS, Sigma-Aldrich) and 20 units penicillin and $20 \mu \mathrm{g}$ streptomycin/mL (Sigma-Aldrich) at $37^{\circ} \mathrm{C}$ in $5 \% \mathrm{CO}_{2}$. For the experiments, the cells were washed with PBS buffer (Sigma-Aldrich) and removed from the bottles by trypsinization (trypsin $0.25 \%$ and EDTA $0.02 \%$, Sigma-Aldrich).

\section{Drugs}

Each drug was freshly prepared each time prior to experiments. ( \pm )-Catechin hydrate (Sigma, Cat. no. C1788) was 
firstly dissolved in $99 \%$ ethanol to the $10 \mathrm{mM}$ concentration and subsequently diluted to $5-200 \mu \mathrm{M}$ concentrations in culture medium for cytotoxicity tests or preincubation. CisDiamineplatinum(II) dichloride (Sigma, Cat. no. 479306) was dissolved in the PBS buffer to the concentration of $5 \mathrm{mM}$ and then diluted with culture medium $(5-200 \mu \mathrm{M})$ for cytotoxicity test or FASC analysis. Doxorubicin hydrochloride (Sigma, Cat. no. 44583) was dissolved in the PBS buffer to the $5 \mathrm{mM}$ concentration and then diluted to $5 \mu \mathrm{M}$ concentration with culture medium for subsequent FACS analysis.

\section{MTT assay}

The MTT assay is a colorimetric quantitative method used to determine the activity of the energy transformation in the mitochondria. The assay is based on the reaction of reducing the yellow, water-soluble tetrazolium salt (MTT) to the purple, water-insoluble formazan crystals. The amount of crystals formed is proportional to the oxido-recuctive activity of the mitochondria, and under strictly defined conditions to the number of viable cells that exhibit metabolic activities.

The adherent cells SKOV-3 were subjected to trypsin to separate from the bottom of the culture flasks. Then, the cells were plated on a multi-well plate in the number of $8 \times$ $10^{3}$ cells/well. Primarily, the cells were incubated for 24 and $48 \mathrm{~h}$ in the presence of $5,10,15,25,50$ or $200 \mu \mathrm{M}$ catechin solution. Similarly, we evaluated the cytotoxicity of the same concentrations of cisplatin. Further, based on the catechin cytotoxicity measurement, the non-toxic concentration of catechin $(10 \mu \mathrm{M})$ was selected for preincubation. The cells were preincubated with $10 \mu \mathrm{M}$ catechin for 2 , 24 and $48 \mathrm{~h}$ and subsequently treated with cisplatin in concentrations ranging from 5 to $200 \mu \mathrm{M}$ for 24 and $48 \mathrm{~h}$. The controls were the cells incubated in culture medium (DMEM), corresponding to $100 \%$ of the mitochondrial activity. At the end of the experiment, the cells were incubated for $2 \mathrm{~h}$ at $37^{\circ} \mathrm{C}$ in MTT solution (3-(4,5-dimethylthiazol-2-yl)-2,5-diphenyltetrazolium bromide, Sigma; $0.5 \mathrm{mg} / \mathrm{ml}$ of PBS buffer); then $100 \mu \mathrm{L}$ of the acidified isopropanol $(0.04 \mathrm{M} \mathrm{HCl}$ in absolute isopropanol) was added to each well to dissolve the formazan crystals. The absorbance of the coloured solution was measured at 570 $\mathrm{nm}$ using the multiplate reader (EnSpire, Perkin Elmer) (Loosdrecht et al. 1994).

\section{Cell death assay}

SKOV-3 cells were plated on 6-well plates at a concentration of $2 \times 10^{5}$ cells/well and incubated for 24 and $48 \mathrm{~h}$ at 5 , $10,15,25,50$ and $200 \mu \mathrm{M}$ cisplatin solution and at 5, 10, $15,25,50$ and $200 \mu \mathrm{M}$ cisplatin solution after 24-hour preincubation in $10 \mu \mathrm{M}$ catechin solution. After incubation, the cells were washed with PBS, trypsinized and stained with Annexin V-APC Apoptosis Kit (BioLegend). Then fluorescent intensities were determined on FACS Calibur flow cytometer (Becton Dickinson).

\section{Immunocytochemical staining}

In order to investigate the role of catechin in the modulation of multidrug resistance, the cells were seeded on 12-well diagnostic microscopic slides (Thermo Fisher Scientific) and the immunoreactivity of P-glycoprotein (P-gp), glutathione S-transferase (GST), breast cancer resistance protein (BCRP) and lung resistance-related protein (LRP) was analysed. Immunocytochemical staining after 2, 24 and $48 \mathrm{~h}$ incubation in the presence of $10 \mu \mathrm{M}$ catechin solution was performed using the ABC method. Briefly, cells were fixed and dehydrated in $4 \%$ paraformaldehyde (PFA, SigmaAldrich, USA) in PBS for 10 minutes and stained with the EXPOSE Mouse and Rabbit Specific HRP/DAB Detection IHC kit (Abcam, United States; Cat. no ab80a36). For the overnight incubation we used the following antibodies: rabbit polyclonal anti-GST (Z-5) (Santa Cruz, Cat. no sc459), mouse monoclonal (F4) anti-P Glycoprotein (Abcam, Cat. no ab80594) and mouse monoclonal anti-LRP (Santa Cruz, Cat. no sc-23917) diluted 1:200 and mouse monoclonal (BXP-21) anti-BCRP (Abcam, Cat. no ab3380) diluted 1:300 with the PBS buffer. Between particular steps samples were rinsed with $1 \%$ Triton $\mathrm{X}-100$ in PBS. To reveal the cell nuclei, the samples were stained with haematoxylin for $3 \mathrm{~min}$. The immunocytochemical reaction was evaluated in a double-blinded manner with an upright microscope (Olympus BX51, Japan) and the percentage of cells with the immunoreaction was estimated. The intensity of immunocytochemical staining was evaluated as: (-) negative, $(+)$ weak, $(++)$ moderate and $(+++)$ strong.

\section{Drug uptake by FACS analysis}

Flow cytometry analysis was performed for the assessment of doxorubicin (DOX) uptake and efflux into the ovarian cancer cells. DOX was selected as a model drug due to its fluorescent ability. SKOV-3 cells were plated on 6-well plates at a concentration of $2 \times 10^{5}$ cells/well and preincubated for 2,24 or $48 \mathrm{~h}$ with $10 \mu \mathrm{M}$ catechin solution. After preincubation, the cells were washed with PBS and subsequently incubated with doxorubicin for $2 \mathrm{~h}$ (reflecting the uptake perfusion), and then with doxorubicin-free medium again for $1 \mathrm{~h}$ (reflecting the efflux perfusion). Intracellular fluorescence of doxorubicin was measured to determine the amount of the drug that enters the cells during a 2-h incubation with doxorubicin (uptake), and what part 
of the dose of the drug is removed from the cells within the next hour (efflux).

Cells were then analysed using a FACS Calibur flow cytometer (Becton Dickinson). The fluorescence of doxorubicin was measured with FL-3 detector. At least 10,000 viable cells were measured from each sample at a rate of up to 1000 cells/s.

\section{Statistics}

Statistical significance was determined by unpaired $t$-Student tests for cytotoxicity tests and two-way analysis of variance (ANOVA) for the toxicity measurements preceded by catechin preincubation. Differences between treated samples and control cells not treated with catechin, with $p$ values $\leq 0.05$ were assumed to be statistically significant. The results were analysed statistically with the Microsoft Office Excel 2010 and GraphPad Prism 7.0 software. Samples were analysed in at least four replications in three independent experiments.

\section{Results}

\section{Cytotoxic properties of catechin and cisplatin}

The obtained results indicate that, catechin has been found to exert much less toxic effect on SKOV-3 cells than cisplatin (Fig. 1a, b). In case of the highest catechin concentration, the decrease of mitochondrial activity after 48-h incubation was $\sim 20 \%$. There was no effect on the mitochondrial activity of cells treated with $5 \mu \mathrm{M}$ catechin solutions. The studies showed that concentrations of catechin in range of $10-25 \mu \mathrm{M}$ caused a slight decrease in cell viability (about 10\%). Cisplatin also inhibited mitochondrial activity of SKOV-3 cells in a dose-dependent manner with the least mitochondrial activity (26\%) after $48 \mathrm{~h}$ of incubation with $200 \mu \mathrm{M}$ cisplatin.

\section{Catechin in modulation of drug resistance to cisplatin}

Our studies showed that cisplatin-resistant SKOV-3 cells can be sensitized to the action of the drug, due to preincubation with catechin at a concentration of $10 \mu \mathrm{M}$ (Fig. 2). However, the effect was prominent only for 24-h preincubation, whereas short-term and long-term preincubation seemed to play a protective role toward resistant ovarian cancer cells. Longer incubation with cisplatin resulted in decreased mitochondrial activity comparing the same cisplatin concentration. The biggest differences (nearly $15 \%$ ) between preincubated and non-preincubated cells were obtained following the exposition to $15 \mu \mathrm{M}$ cisplatin.

\section{Effect of catechin on apoptosis}

In order to test whether cell death occurred on the path of apoptosis or necrosis, the phenotypic changes characteristic for apoptotic cells were analysed and quantified by double staining of SKOV-3 cells with annexin V conjugated with APC and propidium iodide (PI). The study revealed that SKOV-3 cell death increased significantly after cisplatin treatment (Fig. 3a-d). We observed higher level of apoptotic cells after longer incubation with cisplatin, especially for lower cisplatin concentration. However, longer incubation with the highest cisplatin concentration $200 \mu \mathrm{M}$ resulted in lower percentage ratio of apoptotic cells in comparison to shorter treatment with the cytostatic. We also observed increased level of total apoptotic cells after preincubation with catechin (Tables 1 and 2). For higher concentrations of cisplatin, preincubation with catechin resulted in a slight increase in the percentage of apoptotic cells. Longer incubation with cisplatin after pretreatment with catechin caused increased level of total apoptotic cell only for lower cisplatin concentration. We observed similar correlations for cells incubated only with the cytostatic (Fig. 3a, c).
Fig. 1 The cytotoxicity of catechin $\mathbf{a}$ and cisplatin $\mathbf{b}$ after 24 and $48 \mathrm{~h}$ of incubation in the ovarian cancer cell line SKOV3. *statistically significant differences between catechin/ cisplatin-treated groups and nontreated control $(p \leq 0.05)$
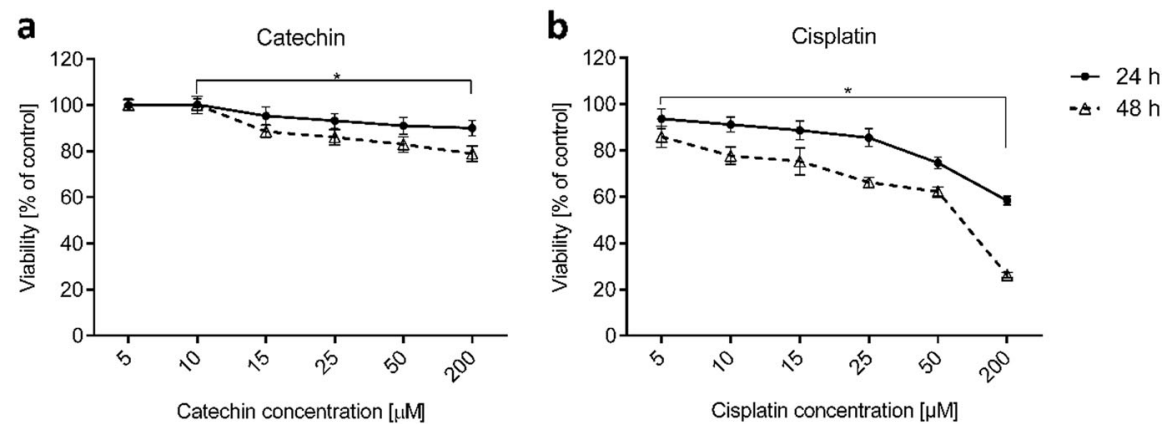


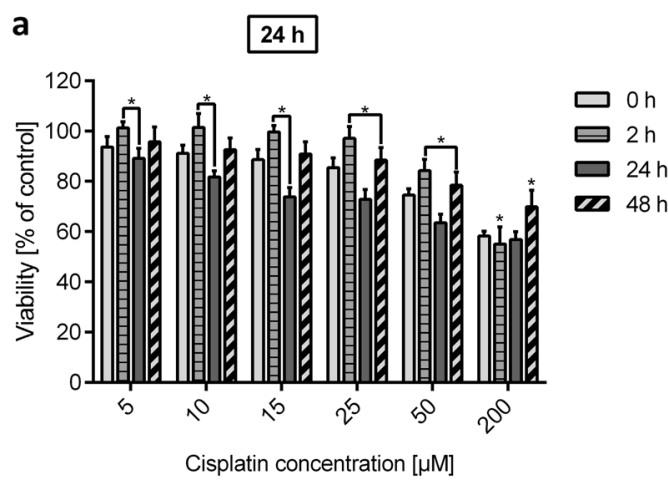

Fig. 2 The cytotoxicity of cisplatin after $0,2,24$ and $48 \mathrm{~h}$ of preincubation with catechin at a concentration of $10 \mu \mathrm{M}$ and $24 \mathrm{~h}$ a and $48 \mathrm{~h} \mathrm{~b}$ of incubation with cisplatin in the ovarian cancer cell line

\section{Effect of catechin on MDR-related protein expression}

Immunocytochemical staining revealed changes in P-gp, GST, BCRP and LPR expression (Fig. 4). The weak expression of P-gp was observed in $100 \%$ of examined SKOV-3 cells, which decreased after incubation with catechin, especially after $24 \mathrm{~h}$. The immunoreactivity of the LRP protein significantly decreased and the effect was stronger for the longer incubation with catechin. More apparent changes occurred in the expression of BCRP, which was reflected by the percentage of stained cells and strength of the reaction. After $24 \mathrm{~h}, 49 \%$ of examined SKOV-3 cells was characterized by a slight expression of BCRP in comparison to the untreated cells, with strong immunoreaction of this protein. Immunocytochemical assay showed a weak expression of GST in ovarian cancer cells incubated with catechin for all experimental conditions. None of the incubation times caused visible disturbances in cellular morphology. Additionally, we revealed that intracellular localization of the examined proteins depends on the time of incubation with catechin. In the case of the cells not incubated as well as incubated with catechin for $2 \mathrm{~h}$ we observed intense intranuclear presence of BCRP protein and perinuclear existence of GST, LRP and P-gp proteins. However, longer incubation with catechin resulted in the presence of these proteins only in cytoplasm except of the cells which were cultured with catechin for $24 \mathrm{~h}$ and showed a slight perinuclear expression of LRP. The percentage ratio of the stained cells is presented in Table 3.

\section{Effect of catechin on drug uptake and efflux}

The uptake and efflux of the chemotherapeutic agent was measured and determined indirectly bythe intracellular fluorescence of doxorubicin after $0,2,24$ and $48 \mathrm{~h}$ of preincubation with $10 \mu \mathrm{M}$ catechin. As shown in the Fig. 5, only 48-h catechin preincubation increased DOX uptake by

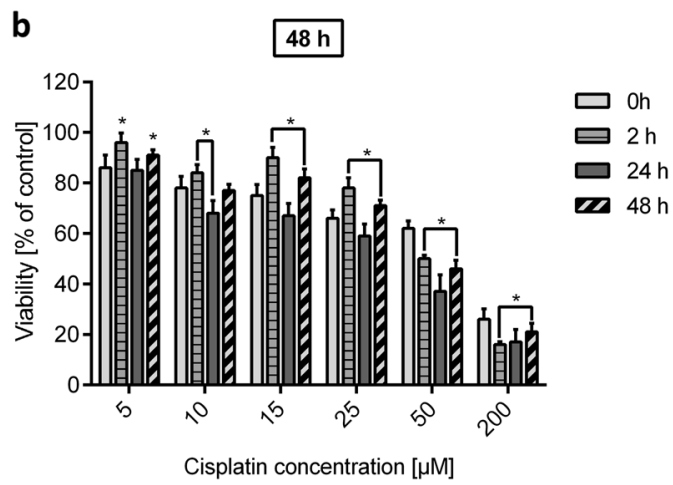

SKOV-3. *statistically significant differences between catechin/cisplatin-treated groups and cisplatin-treated control $(p \leq 0.05)$

ovarian cells. However, at the same time there was a significant decrease in DOX efflux, especially for 24 and 48-h preincubation. That was reflected by increased doxorubicin fluorescence measured $60 \mathrm{~min}$ after subjection to DOX action (Fig. 5).

\section{Discussion}

The modulation of signal transduction pathways, induction of apoptosis, inhibition of cell proliferation, tumour invasion and angiogenesis are mechanisms considered to be the major modulators of carcinogenesis (Gonzalo and DiazPadila 2016). Previous studies (Rao and Pagidas 2010; Trudel et al. 2012) have shown that polyphenolic green tea compounds affect SKOV-3 cell proliferation. Cancer cells treated with epicatechin lose the ability to convert energy in the mitochondria, which indicates that epicatechin causes disruption of the metabolic activity (Trudel et al. 2012). In addition, the tested polyphenol compounds demonstrate the ability to inhibit DNA synthesis and cell proliferation (Rao and Pagidas 2010). Comparing the obtained results to previous reports referring to the influence of polyphenol compounds on SKOV-3 cells, it can be stated that catechin and epicatechin in low concentrations reveal an inhibitory effect on mitochondrial cell activity-epicatechin at a concentration $50 \mu \mathrm{M}$ causes about $17 \%$ decrease in mitochondrial activity (Hosseinimehr et al. 2013), while the same concentration of catechin decreased viability by $21 \%$ in our study. This suggests that catechin may be as potent an inhibitor of tumor cell proliferation as epicatechin. Further research should be aimed at comparing the results of both substances with a particular determination of the changes induced by catechin.

It is believed that the antitumor effect of green tea polyphenols is based on the induction of apoptosis (Dong et al. 1997; Okabe et al. 1999; Hussain et al. 2005), inactivation of transcription factors (Okabe et al. 1999), 
a

w/o preincubation

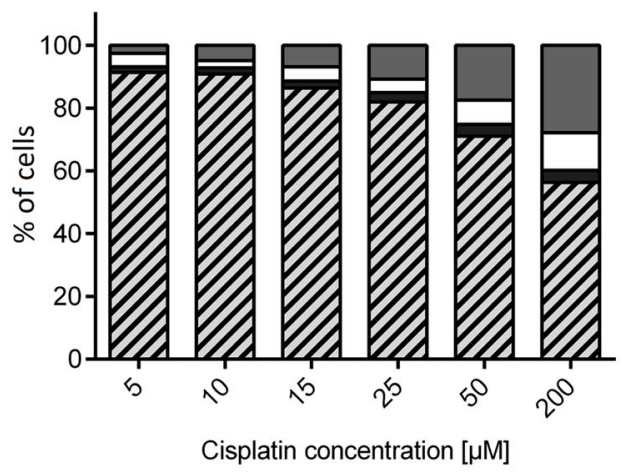

C

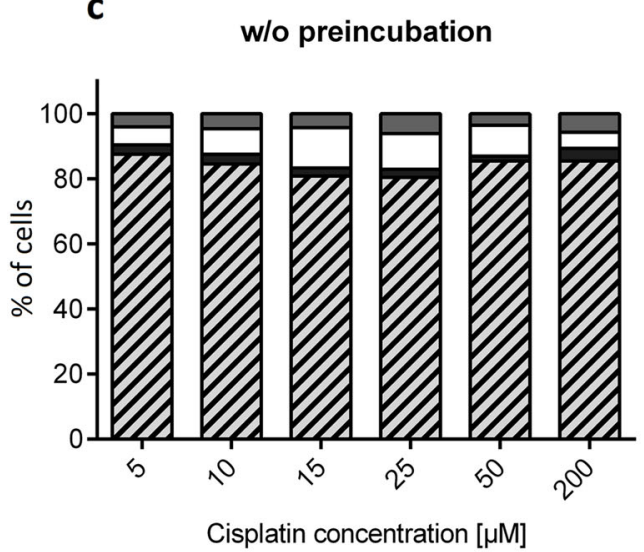

$24 \mathrm{~h}$ b preincubated

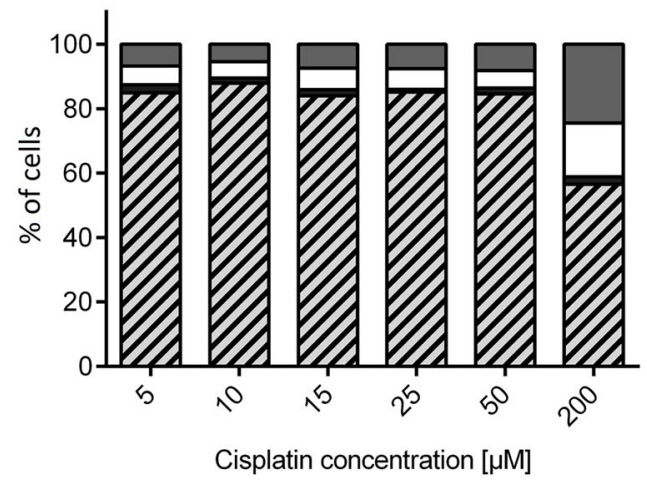

$48 \mathrm{~h} d \quad$ preincubated

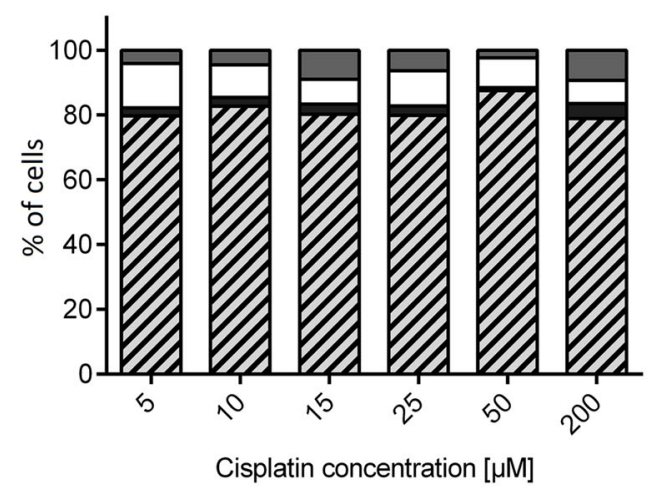

$\square$ late apoptosis

$\square$ apoptosis

necrosis

undamaged

e

Cisplatin concentration $[\mu \mathrm{M}]$

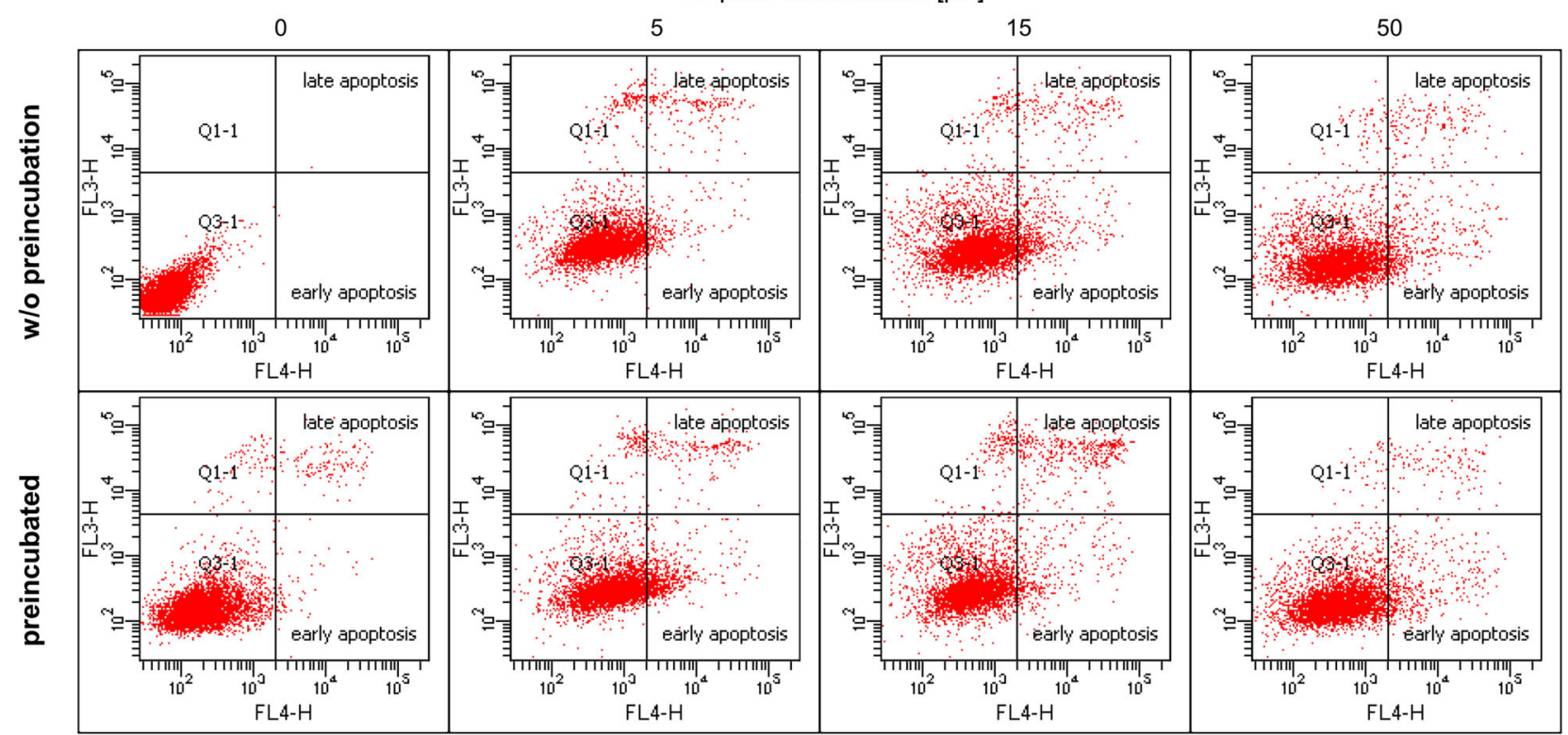

Fig. 3 The percentage ratio of undamaged, necrotic, apoptotic and late apoptotic cells after 24-h incubation with cisplatin a and 24-h incubation with cisplatin after preincubation with $10 \mu \mathrm{M}$ catechin for $24 \mathrm{~h}$ b, after 48-h incubation with cisplatin c, 48-h incubation with cisplatin after preincubation with $10 \mu \mathrm{M}$ catechin for $24 \mathrm{~h}$ d and the representative dot plots presenting the ovarian cancer cells SKOV-3 after 48-h incubation with cisplatin (w/o preincubation) and 48-h incubation with cisplatin after $24-\mathrm{h}$ preincubation (preincubated) with $10 \mu \mathrm{M}$ catechin $\mathbf{e}$ 
Table 1 Cell death evaluation after $24 \mathrm{~h}$ of incubation with cisplatin (w/o preincubation) and $24 \mathrm{~h}$ of preincubation with catechin at a concentration of $10 \mu \mathrm{M}$ (catechin preincubated) in the ovarian cancer cell line SKOV-3

\begin{tabular}{llll}
\hline $\begin{array}{l}\text { Cisplatin concentration } \\
{[\mu \mathrm{M}]}\end{array}$ & Undamaged & $\begin{array}{l}\text { Necrosis } \\
\text { w/o preincubation }\end{array}$ & $\begin{array}{l}\text { Total } \\
\text { apoptosis }\end{array}$ \\
\hline 5 & 92 & 2 & 6 \\
10 & 91 & 2 & 7 \\
15 & 86 & 2 & 12 \\
25 & 82 & 3 & 15 \\
50 & 71 & 4 & 25 \\
200 & 56 & 4 & 40 \\
catechin preincubated & & & \\
5 & 85 & 3 & 12 \\
10 & 88 & 2 & 10 \\
15 & 84 & 2 & 14 \\
25 & 85 & 1 & 14 \\
50 & 85 & 2 & 13 \\
200 & 56 & 2 & 42 \\
\hline
\end{tabular}

Results expressed as percentage of cells

Table 2 Cell death evaluation after $48 \mathrm{~h}$ of incubation with cisplatin (w/o preincubation) and $24 \mathrm{~h}$ of preincubation with catechin at a concentration of $10 \mu \mathrm{M}$ (catechin preincubated) in the ovarian cancer cell line SKOV-3

\begin{tabular}{llll}
\hline $\begin{array}{l}\text { Cisplatin concentration } \\
{[\mu \mathrm{M}]}\end{array}$ & Undamaged & $\begin{array}{l}\text { Necrosis } \\
\text { w/o preincubation }\end{array}$ & $\begin{array}{l}\text { Total } \\
\text { apoptosis }\end{array}$ \\
\hline 5 & 87 & 3 & 10 \\
10 & 84 & 3 & 13 \\
15 & 81 & 3 & 16 \\
25 & 80 & 3 & 17 \\
50 & 85 & 1 & 14 \\
200 & 85 & 4 & 11 \\
catechin preincubated & & & \\
5 & 79 & 3 & 18 \\
10 & 82 & 3 & 15 \\
15 & 80 & 3 & 17 \\
25 & 80 & 3 & 17 \\
50 & 88 & 1 & 11 \\
200 & 79 & 5 & 16 \\
\hline
\end{tabular}

Results expressed as percentage of cells

inhibition of urokinase enzymes (Dong et al. 1997) and cell cycle arrest in G1 phase (Cao et al. 2016). The research performed by Hagen et al. (2013), shows that green tea extract activates the release of cytochrome $\mathrm{c}$ and activates caspases' cascade to induce apoptosis (Hagen et al. 2013). In our study, the population of pre-treated cells with catechin has also shown a higher percentage of apoptosis.
According to the latest reports, epigallocatechin gallate (EGCG) inhibits the activity of topoisomerase I, which plays a key role in replication through participation in DNA condensation (Hussain et al. 2005). EGCG also inhibits the growth of tumour cells by inhibiting the induction of vascular endothelial growth factor (VEGF) in human colorectal cancer cells (Dong et al. 1997; Shankar et al. 2008).

Platinum derivatives are currently the first-choice chemotherapeutics recommended for treatment of ovarian cancer. Cisplatin (cis-diaminadichloroplatinum (II), cDDP) exerts cytotoxic activity, mainly through the formatting the DNA strand, which blocks the transcription and replication, leading to cellular apoptosis. However, drug resistance is an important limitation in the clinical use of cDDP. Mechanisms of resistance to cDDP in ovarian cancer are complicated and can be divided in two groups: (1) those that limit the formation of cytotoxic platinum-DNA adducts, and (2) those that prevent cell death occurrence after platinumDNA adduct formation (Gonzalo and Diaz-Padila 2016). The decreased cellular uptake of cisplatin by resistant cells is one of the major mechanisms of resistance described in vitro. The mechanism responsible for reduced cisplatin accumulation in resistant cells may be ascribed to either an inhibition of drug uptake, the increase in drug efflux, or both (Jamieson, Lippard 1999; Siddik 2003; Gonzalo and Diaz-Padila 2016). The variable expression of proteins involved in multidrug resistance of cancer cells is also associated with cell resistance to doxorubicin. Some data suggested that ABC ATPases such as multidrug resistance protein (MRP)-MRP1, MRP2, MRP3 and MRP5 can mediate some extent of cisplatin resistance by increasing cisplatin export. Thus, mechanisms involved in the active transport of cytotoxic agents such as P-gp, LRP or BCRP may as well play a significant role in cancer drug resistance (Meschini et al. 2002; Liang et al. 2010; Cheng et al. 2016; Han et al. 2018). P-glycoprotein (P-gp), encoded by the multidrug resistance gene MDR1, is an ATP-dependent transport protein located in the cell membranes. It participates in the transport of medicines and other xenobiotics, affecting their absorption, distribution, metabolism and excretion. High P-gp activity in cancer cells is considered to be one of the leading causes of the chemotherapy inefficiency. In medical practice, P-gp substrates are: chemotherapeutic drugs, such as doxorubicin and paclitaxel, but also a number of antibiotics (erythromycin, levofloxacin, tetracyclines), immunosuppressive, antihypertensive and antiviral drugs (Savas et al. 1996). Previous studies have shown that green tea catechins affect the expression of P-glycoprotein and induces the inhibition of this transporter, thereby eliminating drug resistance (Spinella et al. 2006; Liang et al. 2010; Hagen et al. 2013). It has been revealed that the SKOV3 cells did not overexpress P-gp, which corresponds to our observations. 
Table 3 The comparison of the immunoreactivity of the Pglycoprotein (P-gp), lung resistance protein (LRP), breast cancer related protein (BCRP) and glutathione S-transferase (GST) in SKOV-3 cells not exposed to catechin versus the cells preincubated with $10 \mu \mathrm{M}$ catechin for 2, 24 and $48 \mathrm{~h}$

Fig. 4 The representative photographs of the immunoreactivity of the Pglycoprotein (P-gp), lung resistance protein (LRP), breast cancer related protein (BCRP) and glutathione S-transferase (GST) SKOV-3 cells not preceded by catechin preincubation versus preceded by incubation with $10 \mu \mathrm{M}$ catechin for 2, 24 and $48 \mathrm{~h}$

\begin{tabular}{|c|c|c|c|c|c|c|c|c|}
\hline \multirow{2}{*}{$\begin{array}{l}\text { MDR } \\
\text { marker }\end{array}$} & \multicolumn{2}{|c|}{ w/o incubation } & \multicolumn{2}{|l|}{$2 \mathrm{~h}$} & \multicolumn{2}{|l|}{$24 \mathrm{~h}$} & \multicolumn{2}{|l|}{$48 \mathrm{~h}$} \\
\hline & $\begin{array}{l}\% \text { of } \\
\text { stained } \\
\text { cells }\end{array}$ & $\begin{array}{l}\text { Reaction } \\
\text { intensity }\end{array}$ & $\begin{array}{l}\% \text { of } \\
\text { stained } \\
\text { cells }\end{array}$ & $\begin{array}{l}\text { Reaction } \\
\text { intensity }\end{array}$ & $\begin{array}{l}\% \text { of } \\
\text { stained } \\
\text { cells }\end{array}$ & $\begin{array}{l}\text { Reaction } \\
\text { intensity }\end{array}$ & $\begin{array}{l}\% \text { of } \\
\text { stained } \\
\text { cells }\end{array}$ & $\begin{array}{l}\text { Reaction } \\
\text { intensity }\end{array}$ \\
\hline P-gp & 100 & $+/++$ & 100 & + & 59 & $-1+$ & 53 & $-1+$ \\
\hline LRP & 100 & $++/+++$ & 100 & $+/++$ & 87 & + & 89 & + \\
\hline BCRP & 100 & +++ & 100 & $++/+++$ & 49 & $-1+$ & 57 & $-1+$ \\
\hline GST & 100 & + & 100 & + & 13 & $-1+$ & 10 & $-1+$ \\
\hline
\end{tabular}

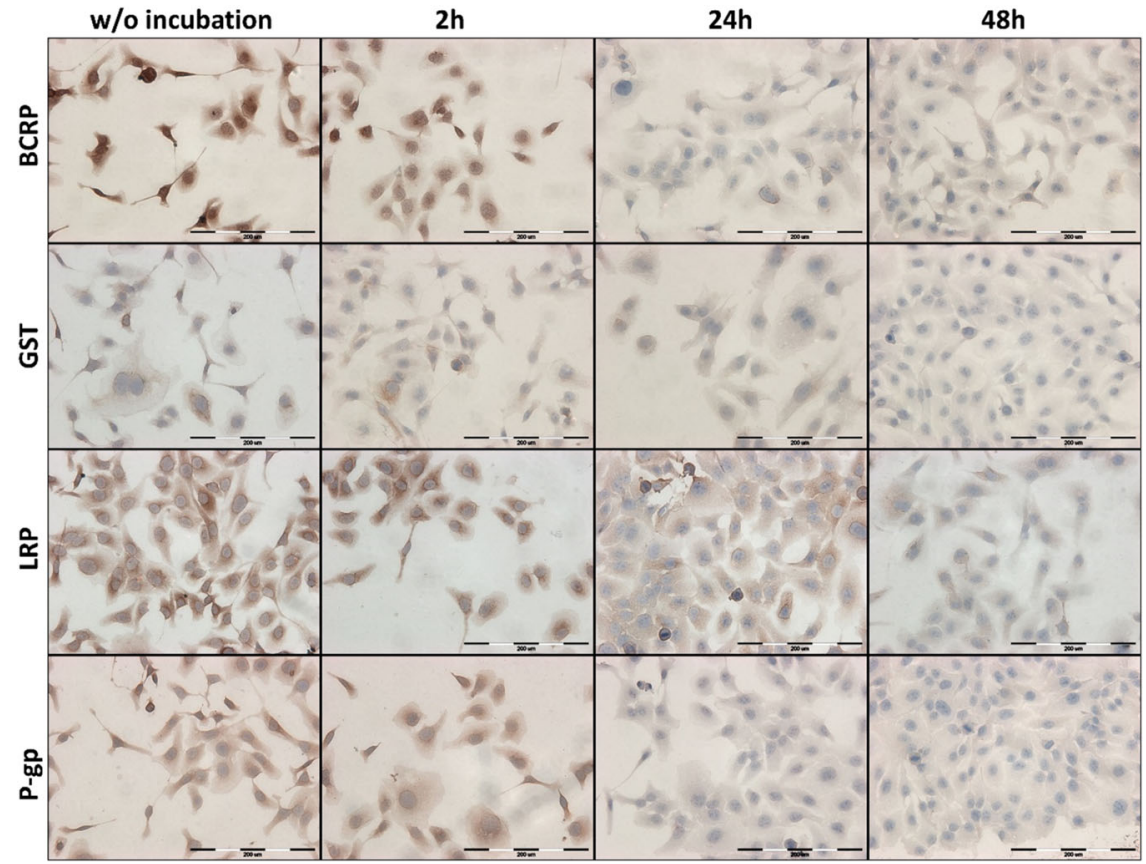

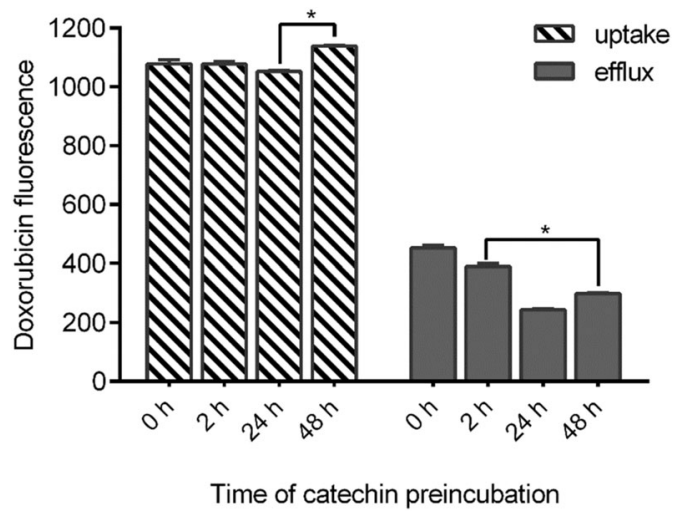

Fig. 5 Doxorubicin uptake and efflux in SKOV-3 cells preincubated with $10 \mu \mathrm{M}$ catechin for $0,2,24$ or $48 \mathrm{~h}$ prior to $2 \mathrm{~h}$ incubation with $5 \mu \mathrm{M}$ doxorubicin

Nevertheless, our studies have shown that catechin can downregulate P-gp. However, cisplatin is not a substrate for the P-gp (Kuppen et al. 1988; Toffoli et al. 1991) and some studies confirm that cisplatin resistance is not associated with P-gp (Duan et al. 2009). Because of this fact the reduced P-gp expression is associated with increased intracellular doxorubicin concentration while it does not play a significant role in cisplatin resistance.

There are also other proteins than P-gp related to multidrug resistance. Some cisplatin resistant cells overexpress a $200 \mathrm{kDa}$ protein and display decreased cellular accumulation of cisplatin, suggesting that this protein may be involved in cisplatin efflux (Shi et al. 2014). Moreover, cisplatin conjugated with glutathione may be pumped out through the ATP-dependent glutathione S-conjugate export pump, which might be involved in reducing the intracellular cisplatin concentration in cisplatin-resistant cells (Ishikawa and Ali-Osman 1993; Chen et al. 1998; Kartalou and Essigmann 2001). There are also other proteins that regulate the drug uptake, and are associated with overexpression of cooper transporter CTR1 (Song et al. 2004; Samimi et al. 2004). It is known that green tea compounds enhance expression of the CTR1 in ovarian cancer and SKOV-3 cells (Wang et al. 2015; Kilari et al. 2016). This suggests that an increased cisplatin cytotoxicity in co-treatment with 
green tea polyphenols can be associated with the reduced expression of proteins involved in pumping up drugs into cells. However, the intracellular doxorubicin uptake did not change significantly after preincubation with $( \pm)$-Catechin.

The other mechanism related to the cell protection against drugs is glutathione (gamma-glutamylcysteinylglycine: GSH). GSH contributes to the detoxication of many cellular toxins, including cisplatin and its analogues. Part of the cytoplasmic cisplatin reacts with DNA; however, a major fraction of intracellular cisplatin is converted into cisplatin-thiol conjugates by GSH-S-transferase $\pi$ (GST- $\pi$ ), and these conjugates are non-cytostatic. Both GST $\pi$ and $\gamma$ glutamylcysteine synthetase $(\gamma$ - GCS) have been associated with cisplatin resistance in cervical, ovarian and lung cancer cell lines (Sakamoto et al. 2001; Kelland 2007; Li et al. 2009) and reducing intracellular GSH levels would seem a promising strategy to overcome the platinum resistance (Gonzalo and Diaz-Padila 2016). Immunohistochemical analysis showed that the expression of GST increased significantly in ovarian cancer compared to regular ovarian tissue or benign ovarian tumours (Lu et al. 2011). However, in SKOV-3 cells there is a weak expression of GST (Gonera et al. 2014; Zhang et al. 2015b) as we confirmed semiquantitatively in our study. Liang et al. (2010) discovered that green tea catechins did not alter GST protein level in tumour (Liang et al. 2010). Here, we observed that catechin decreased the percentage of GST immunoreactivity in SKOV-3 cells after preincubation with catechin.

As we mentioned and confirmed in our studies, SKOV-3 cells are characterised by overexpression of LRP (Shi et al. 2014). Lung resistance protein (LRP) prevents nuclei from entering chemotherapeutics into the nuclei, pumps drugs into cytoplasmic vesicles and pumps the medicine out of cells to decrease the intracellular drug concentration, thus causing drug resistance (Sedláková et al. 2012; Zhang et al. 2015 b). LRP is involved in the resistance of ovarian cancer cells to cisplatin and doxorubicin and has an important role in the transport between the nucleus and cytoplasm and intranuclear chemotherapeutics concentration (Meschini et al. 2002; Wang et al. 2004). In ovarian cancer cells, LRP down-regulation reversed drug resistance, increased cellular cDDP accumulation, increased cDDP in nuclei, and decreased cDDP efflux from nuclei which enhances cisplatin cytotoxicity (Wang et al. 2004). It is known that EGCG from green tea does not alter LRP expression in liver cancer cells (Liang et al. 2010). However, our study has revealed a significant decrease of the LRP protein amount after catechin treatment in SKOV-3 cells that can be associated with an increased intracellular drug concentration and cytotoxicity, which was confirmed in this study.

Our studies demonstrated overexpression of BCRP in SKOV-3 cells. Breast cancer resistance protein (BCRP) is a member of the ATP-binding cassette superfamily of transporters presented on cell membranes (Doyle et al. 1998). Previous studies have shown that green tea compounds are able to downregulate BCRP in MCF-7 cells (Farabegoli et al. 2010), but have no inhibitory effect on Pgp and BCRP in LLC-PK1 and MDCK-II cells (Fleisher et al. 2015). Our research indicates that catechin also significantly downregulates BCRP. Nakayama et al. (2002) indicated rather frequent expression of BCRP gene (44/82, $53.7 \%$ ) in human ovarian carcinoma, but BCRP expression level was not a prognostic indicator of disease, and concluded that BCRP might not play an important role in ovarian carcinomas treated with cisplatin-based chemotherapy (Nakayama et al. 2002). The downregulation of BCRP preceded by catechin preincubation points out that catechin can be effectively used in the treatment with BCRP substrates such as doxorubicin, which was confirmed by increased DOX uptake revealed in a FACS analysis.

The comparison of viability assay results and cell death analysis after preincubation with catechin disclose interesting conclusions. Our research indicates a significant impact of catechin preincubation on SKOV-3 cells prior to chemotherapy in vitro. There was an apparent decrease in mitochondrial activity up to $36 \%$ after $24 \mathrm{~h}$ of incubation with cisplatin at concentration of $50 \mu \mathrm{M}$. However, the cytometric analysis indicated that the total percentage of necrotic cells, early and late apoptotic, accounts for $\sim 15 \%$. The obtained differences may suggest that catechin and cisplatin combination therapy also leads to cell death in a different way than only due to apoptosis and necrosis. For example, previous studies indicated that green tea polyphenols could stimulate autophagy (Siddik 2003; Han et al. 2018).

The available bioinformatic analyses based on online databases confirm the anti-cancer properties of green tea polyphenols. According to Xinqiang et al. (2017) there are several cellular pathways through which green tea compounds can reduce the risk of ovarian cancer; these pathways mainly concern cell death and survival, cell growth and proliferation, cellular development, cell morphology, organ morphology, DNA replication, recombination and repair, cell cycle, assembly and organization of stem cells, post-transcriptional modifications and protein synthesis. They also identified several specific proteins that most likely participate in the regulation of ovarian cancer cells, including: JUN, FADD, NFKB1, Bcl-2, HIF1 $\alpha$ and MMP (Xinqiang et al. 2017).

\section{Conclusions}

The presented here research and available reports prove that catechin and its derivatives can potentially be used in chemotherapy, especially in adjunctive, combined and 
personalized therapies, as evidenced by studies and reports on their role in modulation of multidrug resistance, especially associated with decreased expression of Pgp, LRP, BRCP and GST. Catechin may promote death through apoptosis and inhibit ovarian cancer cell proliferation. Green tea polyphenol can modulate multidrug resistance, increase drug uptake and decrease drug efflux, which enhances its cytostatic toxicity.

Acknowledgements The work was created as part of the activity of the Student Research Group "Biology of Cancer Cell" at the Wroclaw Medical University (SKN No. K 148). The research was supported partially by the Statutory Funds of Wroclaw Medical University No.: ST.E130.16.060. (PI: M. Zalewski) and by "Najlepsi z Najlepszych 3.0" PO WER (2014-2020) programme founded by Polish Ministry of Science and Higher Education. We would also like to thank Ms. E. Przydatek for the correction of the English language in the manuscript.

\section{Compliance with ethical standards}

Conflict of interest The authors declare that they have no conflict of interest.

Publisher's note: Springer Nature remains neutral with regard to jurisdictional claims in published maps and institutional affiliations.

Open Access This article is distributed under the terms of the Creative Commons Attribution 4.0 International License (http://crea tivecommons.org/licenses/by/4.0/), which permits use, duplication, adaptation, distribution, and reproduction in any medium or format, as long as you give appropriate credit to the original author(s) and the source, provide a link to the Creative Commons license, and indicate if changes were made.

\section{References}

Amin L (2013) P-glycoprotein inhibition for optimal drug delivery. Drug Target Insights 7:27-34. https://doi.org/10.4137/DTI. S12519

Asano Y, Okarnura S, Ogo T et al. (1997) Effect of (-)-epigallocatechin gallate on leukemic blast cells from patients with acute myeloblastic leukemia. Life Sci 60:135-142

Cao J, Han J, Xiao H et al. (2016) Effect of tea polyphenol compounds on anticancer drugs in terms of anti-tumor activity, toxicology, and pharmacokinetics. Nutrients. https://doi.org/10.3390/ nu8120762

Chen Z-S, Mutoh M, Sumizawa T et al. (1998) An active efflux system for heavy metals in cisplatin-resistant human $\mathrm{kb}$ carcinoma cells. Exp Cell Res 240:312-320. https://doi.org/10.1006/EXCR.1998. 3938

Cheng T, Liu J, Ren J et al. (2016) Green tea catechin-based complex micelles combined with doxorubicin to overcome cardiotoxicity and multidrug resistance. Theranostics 6:1277-1292. https://doi. org/10.7150/thno. 15133

Dong Z, Ma W, Huang C et al. (1997) Targeting multiple signaling pathways by green tea polyphenol (-)-epigallocatechin-3-gallate. Cancer Res 57:4414-4419. https://doi.org/10.1158/0008-5472.ca n- $05-3636$

Doyle LA, Yang W, Abruzzo LV et al. (1998) A multidrug resistance transporter from human MCF-7 breast cancer cells. Proc Natl Acad Sci USA 95:15665-15670
Duan Z, Choy E, Jimeno JM et al. (2009) Diverse cross-resistance phenotype to ET-743 and PM00104 in multi-drug resistant cell lines. Cancer Chemother Pharmacol 63:1121-1129. https://doi. org/10.1007/s00280-008-0843-2

Farabegoli F, Papi A, Bartolini G et al. (2010) (-)-Epigallocatechin-3gallate downregulates Pg-P and BCRP in a tamoxifen resistant MCF-7 cell line. Phytomedicine 17:356-362. https://doi.org/10. 1016/j.phymed.2010.01.001

Fleisher B, Unum J, Shao J, An G (2015) Ingredients in fruit juices interact with dasatinib through inhibition of BCRP: a new mechanism of beverage-drug interaction. J Pharm Sci 104:266275. https://doi.org/10.1002/jps.24289

Gonera A, Wawryka J, Sobkowicz A et al. (2014) SKOV-3 and Me45 cell response to cisplatin-based chemotherapy: an in vitro study. Folia Biol 60:213-219

Gonzalo T, Diaz-Padila I (2016) Molecular mechanisms of platinum resistance in ovarian cancer. In: Dias-Padila I (ed.) Ovarian Cancer-A Clinical and Translational Update. IntechOpen, London, pp 205-223

Hagen RM, Chedea VS, Mintoff CP et al. (2013) Epigallocatechin-3gallate promotes apoptosis and expression of the caspase 9a splice variant in PC3 prostate cancer cells. Int J Oncol 43:1-7. https://doi.org/10.3892/ijo.2013.1920

Han N-N, Li X, Tao L, Zhou Q (2018) Doxorubicin and rhein loaded nanomicelles attenuates multidrug resistance in human ovarian cancer. Biochem Biophys Res Commun 498(1):178-185. https:// doi.org/10.1016/j.bbrc.2018.01.042

Helm CW, States JC (2009) Enhancing the efficacy of cisplatin in ovarian cancer treatment-could arsenic have a role. J Ovarian Res 7:1-7. https://doi.org/10.1186/1757-2215-2-2

Hosseinimehr SJ, Rostamnejad M, Ghaffari-rad V (2013) Epicatechin enhances anti-proliferative effect of bleomycin in ovarian cancer cell. Res Mol Med 1:24-27

Hussain T, Gupta S, Adhami VM, Mukhtar H (2005) Green tea constituent epigallocatechin-3-gallate selectively inhibits COX-2 without affecting COX-1 expression in human prostate carcinoma cells. Int J Cancer 113:660-669. https://doi.org/10.1002/ijc. 20629

Ishikawa T, Ali-Osman F (1993) Glutathione-associated cis-diamminedichloroplatinum(II) metabolism and ATP-dependent efflux from leukemia cells. Molecular characterization of glutathioneplatinum complex and its biological significance. J Biol Chem 268:20116-20125

Jamieson ER, Lippard S (1999) Structure, recognition, and processing of cisplatin-DNA adducts. Chem Rev 99:2467-2498

Kartalou M, Essigmann JM (2001) Mechanisms of resistance to cisplatin. Mutat Res 478:23-43. https://doi.org/10.1016/S0027-5107 (01)00141-5

Kelland L (2007) The resurgence of platinum-based cancer chemotherapy. Nat Rev Cancer 7:573-584. https://doi.org/10.1038/ $\operatorname{nrc} 2167$

Kilari D, Guancial E, Kim ES (2016) Role of copper transporters in platinum resistance. World J Clin Oncol 7:106-113. https://doi. org/10.5306/wjco.v7.i1.106

Kornafel J, Mądry R (2013) Nowotwory kobiecego układu płciowego. In: Krzakowski M, Warzocha K (Eds.) Zalecenia postępowania diagnostyczno-terapeutycznego w nowotworach złośliwych 2013 rok. Via Medica, Gdańsk, pp 265-317

Kuppen PJ, Schuitemaker H, van't Veer LJ et al. (1988) cis-diamminedichloroplatinum(II)-resistant sublines derived from two human ovarian tumor cell lines. Cancer Res 48:3355-3359

Li M, Balch C, Montgomery JS et al. (2009) Integrated analysis of DNA methylation and gene expression reveals specific signaling pathways associated with platinum resistance in ovarian cancer. BMC Med Genom 2:34. https://doi.org/10.1186/1755-8794-2-34 
Liang G, Tang A, Lin X et al. (2010) Green tea catechins augment the antitumor activity of doxorubicin in an in vivo mouse model for chemoresistant liver cancer. Int J Oncol 37:111-123. https://doi. org/10.3892/ijo

Loosdrecht AA, Bellen RHJ, Ossenkoppele gGJ, Broekhoven MG, Langenhuijsen MMAC (1994) A tetrazolium-based colorimetric MTT assay to quantitate human monocyte mediated cytotoxicity against leukemic cells from cell lines and patients with acute myeloid leukemia. J Immunol Methods 174:311-320. https://doi. org/10.1016/0022-1759(94)90034-5

Lu D, Shi H-C, Wang Z-X et al. (2011) Multidrug resistanceassociated biomarkers PGP, GST-pi, Topo-II and LRP as prognostic factors in primary ovarian carcinoma. Br J Biomed Sci 68:69-74

Meschini S, Marra M, Calcabrini A et al. (2002) Role of the lung resistance-related protein (LRP) in the drug sensitivity of cultured tumor cells. Toxicol Vitr 16:389-398

Nakayama K, Kanzaki A, Ogawa K et al. (2002) Copper-transporting P-type adenosine triphosphatase (ATP7B) as a cisplatin based chemoresistance marker in ovarian carcinoma: comparative analysis with expression ofMDR1,MRP1,MRP2,LRP andBCRP. Int J Cancer 101:488-495. https://doi.org/10.1002/ijc.10608

Okabe S, Ochiai Y, Aida M, Park K, Kim SJ, Nomura T, Suganuma MFH (1999) Mechanistic aspects of green tea as a cancer preventive: effect of components on human stomach cancer cell lines. Jpn J Cancer Res 90:733-739

Paschka AG, Butler R (1998) Induction of apoptosis in prostate cancer cell lines by the green tea component, (-) -epigallocatechin-3gallate. Cancer Lett 130:1-7

Rao SD, Pagidas K (2010) Epigallocatechin-3-gallate, a natural polyphenol, inhibits cell proliferation and induces apoptosis in human ovarian cancer cells. Anticancer Res 30:2519-2523

Sakamoto M, Kondo A, Kawasaki K et al. (2001) Analysis of gene expression profiles associated with cisplatin resistance in human ovarian cancer cell lines and tissues using cDNA microarray. Hum Cell 14:305-315

Samimi G, Katano K, Holzer AK et al. (2004) Modulation of the cellular pharmacology of cisplatin and its analogs by the copper exporters ATP7A and ATP7B. Mol Pharmacol 66:25-32. https:// doi.org/10.1124/mol.66.1.25

Savas B, Cole SPC, Tsuruo T, Pross HF (1996) P-Glycoproteinmediated multidrug resistance and lymphokine-activated killer cell susceptibility in ovarian carcinoma. J Clin Immunol 16:348-357

Schuijer M, Berns EMJJ (2003) TP53 and ovarian cancer. Hum Mutat 21:285-291. https://doi.org/10.1002/humu.10181

Sedláková I, Laco J, Tošner J et al. (2012) Proteins of resistance and drug resistance in ovarian carcinoma patients. Klin Onkol $25: 457-463$

Shankar S, Ganapathy S, Hingorani SR, Srivastava RK (2008) EGCG inhibits growth, invasion, angiogenesis and metastasis of pancreatic cancer. Front Biosci 13:440-452. https://doi.org/10.2741/2691

Shi L, Yu H, Zhang W et al. (2014) Establishment and biological characteristics of a platinum-resistance nude mouse model in epithelial ovarian cancer. Zhonghua Fu Chan Ke Za Zhi 49:523-530
Siddik ZH (2003) Cisplatin: mode of cytotoxic action and molecular basis of resistance. Oncogene 22:7265-7279. https://doi.org/10. 1038/sj.onc. 1206933

Song I-S, Savaraj N, Siddik ZH et al. (2004) Role of human copper transporter Ctr1 in the transport of platinum-based antitumor agents in cisplatin-sensitive and cisplatin-resistant cells. Mol Cancer Ther 1:1543-1549

Song Y, Sun H, Zhang A et al. (2014) Plant-derived natural products as leads to anti-cancer drugs. J Med Plant Herb Ther Res 2:6-15

Spinella F, Rosano L, Castro VDi et al. (2006) Green tea polyphenol epigallocatechin-3-gallate inhibits the endothelin axis and downstream signaling pathways in ovarian carcinoma. Am Assoc Cancer Res 5:1483-1493. https://doi.org/10.1158/1535-7163. MCT-06-0053

Sugihara N, Kuroda N, Watanabe F et al. (2017) Effects of catechins and their related compounds on cellular accumulation and efflux transport of mitoxantrone in Caco-2 cell monolayers. J Food Sci 82:1224-1230. https://doi.org/10.1111/1750-3841.13680

Tang H-H, Zhou M, Liang G (2008) Impact of epigallocatechin gallate on gene expression profiles of human hepatocellular carcinoma cell lines BEL7404/ADM and BEL7402/5-FU. Ai Zheng 27:1056-1064

Toffoli G, Viel A, Tumiotto L et al. (1991) Pleiotropic-resistant phenotype is a multifactorial phenomenon in human colon carcinoma cell lines. Br J Cancer 63:51-56

Trudel D, Labbé DP, Bairati I et al. (2012) Green tea for ovarian cancer prevention and treatment: a systematic review of the in vitro, in vivo and epidemiological studies. Gynecol Oncol 126:491-498. https://doi.org/10.1016/j.ygyno.2012.04.048

Wang W, Ke S, Chen G et al. (2004) Effect of lung resistance-related protein on the resistance to cisplatin in human ovarian cancer cell lines. Oncol Rep 12:1365-1370

Wang X, Jiang P, Wang P et al. (2015) EGCG enhances cisplatin sensitivity by regulating expression of the copper and cisplatin influx transporter CTR1 in ovary cancer. PLoS One 10:e125402. https://doi.org/10.1371/journal.pone.0125402

Xinqiang S, Mu Z, Lei C, Mun LY (2017) Bioinformatics analysis on molecular mechanism of green tea compound epigallocatechin-3gallate against ovarian cancer. Clin Transl Sci 10:302-307. https://doi.org/10.1111/cts. 12470

Yang CS, Lambert JD, Sang S (2009) Antioxidative and anticarcinogenic activities of tea polyphenols. Arch Toxicol 83:1121. https://doi.org/10.1007/s00204-008-0372-0

Zhang N, Zhang H, Xia L et al. (2009) NSC606985 induces apoptosis, exerts synergistic effects with cisplatin, and inhibits hypoxiastabilized HIF-1 a protein in human ovarian cancer cells. Cancer Lett 278:139-144. https://doi.org/10.1016/j.canlet.2008.12.025

Zhang Y, Xu Q, Lu J et al. (2015a) Tea consumption and the incidence of cancer: a systematic review and meta-analysis of prospective observational studies. Eur J Cancer Prev 24:353-362. https://doi. org/10.1097/CEJ.0000000000000094

Zhang Z, Xie Z, Sun G et al. (2015b) Reversing drug resistance of cisplatin by hsp90 inhibitors in human ovarian cancer cells. Int $\mathbf{J}$ Clin Exp Med 8:6687-6701 